\title{
ANALISIS K-MEANS CLUSTER PADA KABUPATEN/KOTA DI PROVINSI BANTEN BERDASARKAN INDIKATOR INDEKS PEMBANGUNAN MANUSIA
}

\author{
Rindang Ndaru Puspita ${ }^{1}$ \\ ${ }^{1}$ Statistisi Ahli Pertama Dinas Kependudukan dan Pencatatan Sipil Kabupaten Tangerang \\ Email : rindangnp31@gmail.com
}

\begin{abstract}
The Human Development Index (HDI) is one of the parameters of success in the development of the quality of human life, besides that at the regional level, the HDI is an indicator of the main performance measurement and allocation of Regional Incentive Funds in promoting the welfare of the people in the area. In 2020 the Banten Province Human Development Index 72.45 only rose 0.01\% compared to 2019, lower than the growth in 2019 which reached $0.68 \%$ and is still stuck in the high category $(70 \leq H D I \leq 80)$, this indicates the progress of human development in Banten experienced a slowdown, In addition, when compared to the growth of the HDI-forming indicators in 2019, all components that make up the HDI experienced a slowdown in growth except for RLS which experienced growth acceleration of $0.33 \%$ from $1.39 \%$ in 2019 to $1.72 \%$ in 2020. So it is necessary to do a deeper analysis to determine the characteristics of the indicators that make up the HDI in the City as a contributor to the HDI value of the Banten Province, so that efforts can be made to increase human development as evidence of improving the welfare of the people in the Banten Province. The K-Means Cluster method is used to group cities in Banten Province based on similar characteristics in terms of the HDI compiler indicators which include Life Expectancy at Birth, Expected Years of Schooling, Average Length of Schoolin, and Expenditure per Capita. Based on the results of the analysis obtained three clusters consisting of cities with similar characteristics in each cluster. Cluster 1 is a City with a low HDI indicator consisting of Pandeglang, Lebak, Serang. Cluster 2 is a City with a medium HDI indicator consisting of Tangerang, Cilegon, Serang City. Cluster 3 is a City with a high HDI indicator consisting of Tangerang City and South Tangerang City. After obtaining City information based on the characteristics of each cluster, then the Banten Provincial government can provide direction and policies to each City in Clusters 1 and 2 to be able to develop activity programs with more attention to the HDI compiler indicators, so that the Human Development Index in the City can increase.
\end{abstract}

Keywords: Human Development Index, Clustering, K-Means Cluster 


\begin{abstract}
Abstrak
Indeks Pembangunan Manusia (IPM) merupakan salah satu parameter kesuksesan dalam pembangunan kualitas hidup manusia, selain itu pada tingkat daerah IPM merupakan indikator pengukuran kinerja utama dan pengalokasian Dana Insentif Daerah (DID) dalam mendorong kesejahteraan masyarakat di daerah tersebut. Pada tahun 2020 Indeks Pembangunan Manusia Provinsi Banten 72.45 hanya naik 0.01\% jika dibandingkan tahun 2019, lebih rendah dari pertumbuhan tahun 2019 yang mencapai $0.68 \%$ dan masih tertahan di kategori tinggi $(70 \leq \mathrm{IPM} \leq 80)$, hal ini menandakan kemajuan pembangunan manusia di Provinsi Banten pada tahun 2020 mengalami perlambatan, selain itu Jika dibandingkan pertumbuhan indikator pembentuk IPM di tahun 2019, semua komponen pembentuk IPM mengalami perlambatan pertumbuhan kecuali RLS yang mengalami percepatan pertumbuhan $0.33 \%$ dari $1.39 \%$ pada tahun 2019 menjadi $1.72 \%$ pada tahun 2020. Sehingga Perlu dilakukan analisis lebih dalam untuk mengetahui karakteristik indikator-indikator penyusun IPM di Kabupaten/Kota sebagai penyumbang nilai IPM Provinsi Banten, agar dapat dilakukan upaya untuk peningkatan pembangunan manusia sebagai bukti peningkatan kesejahteraan masyarakat di wilayah Provinsi Banten. Maka perlu dilakukan pengelompokan Kabupaten/Kota di Provinsi Banten berdasarkan kemiripan karakteristik yang ditinjau dari indikator penyusun IPM yang meliputi Umur Harapan Hidup saat Lahir, Harapan Lama Sekolah, Rata-Rata Lama Sekolah, dan Pengeluaran Riil per Kapita per Tahun yang Disesuaikan dengan metode analisis K-Means Cluster. Berdasarkan hasil analisis diperoleh tiga cluster yang terdiri dari Kabupaten/Kota dengan persamaan karakteristik pada masing-masing cluster. Cluster 1 adalah Kabupaten/Kota dengan indikator IPM rendah yaitu Kabupaten Pandeglang, Kabupaten Lebak, Kabupaten Serang. Cluster 2 adalah Kabupaten/Kota dengan indikator IPM sedang terdiri dari Kabupaten Tangerang, Kota Cilegon, Kota Serang. Cluster 3 adalah Kabupaten/Kota dengan indikator IPM tinggi terdiri dari Kota Tangerang dan Kota Tangerang Selatan. Setelah diperoleh informasi Kabupaten/Kota berdasarkan karakteristik masing-masing cluster, maka selanjutnya pemerintah Provinsi Banten dapat memberikan arahan dan kebijakan kepada masing-masing Kabupaten/Kota di Cluster 1 dan 2 untuk dapat menyusun program kegiatan dengan lebih memperhatikan indikator IPM, sehingga Indeks Pembangunan Manusia di Kabupaten/Kota tersebut dapat meningkat.
\end{abstract}

Kata kunci: Indeks Pembangunan Manusia, Clustering, K-Means Cluster

Received: September 15, 2021 / Accepted: December 01, 2021 / Published Online: December 30, 2021 
Jurnal Lebesgue: Jurnal Ilmiah Pendidikan Matematika, Matematika dan Statistika

Rindang Ndaru Puspita, S.Si.

Volume 2, No. 3, Desember 2021 hal.267-281

DOI Artikel: 10.46306/lb.v2i3.85

\section{PENDAHULUAN}

Indeks Pembangunan Manusia (IPM) adalah salah satu parameter yang penting untuk mengukur kesuksesan pembangunan kualitas hidup manusia. Selain itu, sebagai indikator target dalam pembangunan dan proses pengalokasian penentuan Dana Alokasi Umum (DAU) agar optimal serta berperan penting dalam pengukuran kinerja utama dan pengalokasian Dana Insentif Daerah (DID) untuk mendorong kesejahteraan masyarakat.

Secara periodik setiap tahun Badan Pusat Statistik (BPS) menyajikan IPM pada tingkat Nasional, Provinsi, serta Kabupaten/ Kota. Sehingga dapat diketahui peta pembangunan manusia di daerah masing-masing, baik capaian, kecepatan, posisi, maupun kesenjangan antar daerah. IPM dibentuk dari tiga dimensi dengan masing-masing indikator yaitu:

1. Umur Panjang dan Hidup Sehat (a long and healthy life) dengan indikator Umur Harapan Hidup saat Lahir (UHH)

2. Pengetahuan (knowledge) dengan indikator Harapan Lama Sekolah (HLS) dan RataRata Lama Sekolah (RLS)

3. Standar Hidup Layak (decent standard of living) dengan indikator Pengeluaran Riil per Kapita per Tahun yang Disesuaikan

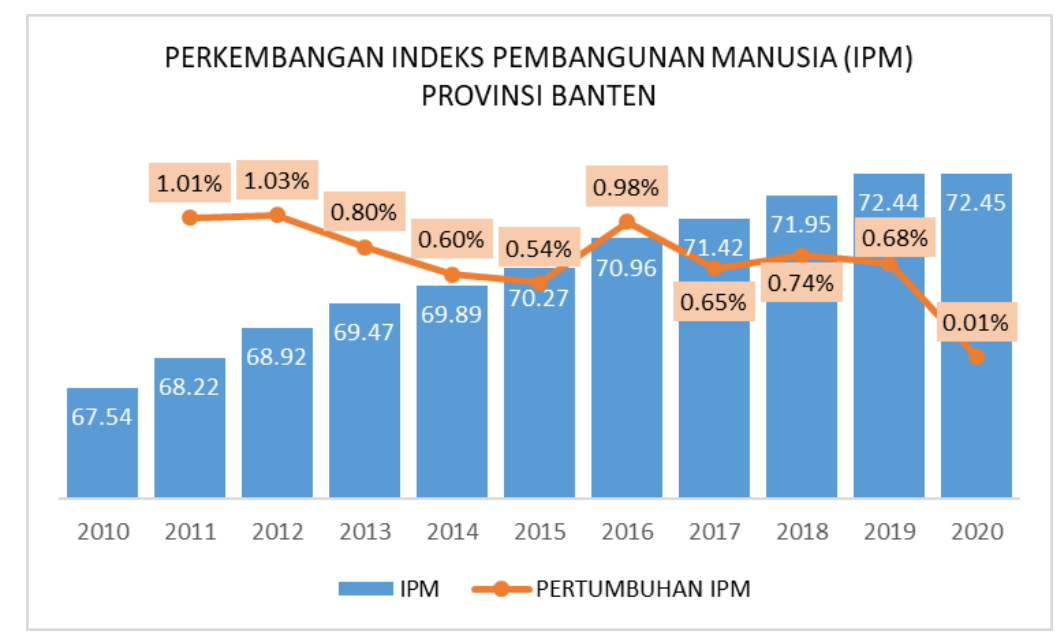

Gambar 1. Perkembangan IPM Provinsi Banten Tahun 2010-2020

Pada Gambar 1 diperoleh informasi tahun 2020 Indeks Pembangunan Manusia Provinsi Banten 72.45 hanya naik 0.01\% jika dibandingkan tahun 2019 dengan nilai IPM 72.44, jika dibandingkan pertumbuhan IPM tahun 2020 dengan 2019 maka hasilnya lebih rendah karena tahun 2019 pertumbuhan IPM mencapai 0.68\%. Selain itu, IPM masih tertahan di kategori tinggi (70 $\leq$ IPM $\leq 80)$, hal ini menandakan perlambatan kemajuan pembangunan manusia di Provinsi Banten pada tahun 2020. 


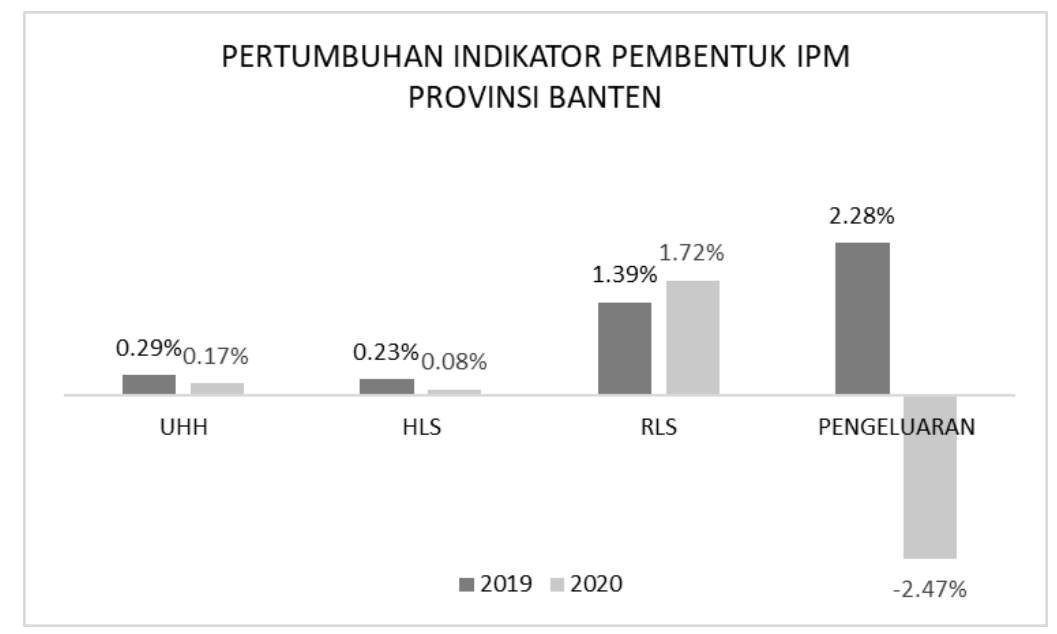

Gambar 2. Pertumbuhan Indikator Pembentuk IPM Provinsi Banten

Berdasarkan gambar 2 Pada tahun 2020 terjadi peningkatan pada 3 indikator IPM yaitu UHH, HLS, RLS sedangkan Pengeluaran Riil per Kapita per Tahun mengalami penurunan 2.47 $\%$ dibandingkan tahun 2019. Jika dibandingkan pertumbuhan indikator pembentuk IPM di tahun 2019, semua komponen pembentuk IPM mengalami perlambatan pertumbuhan kecuali RLS yang mengalami percepatan pertumbuhan $0.33 \%$ dari $1.39 \%$ pada tahun 2019 menjadi 1.72\% tahun 2020. Hal ini menunjukkan rata-rata lama sekolah meningkat sehingga dapat diartikan kualitas pendidikan di provinsi banten mengalami peningkatan. Sedangkan umur harapan hidup saat lahir (UHH) yang menggambarkan umur panjang serta hidup sehat, harapan lama sekolah (HLS) yang menunjukkan peluang semakin banyaknya penduduk yang dapat sekolah serta penanda perbaikan pada sistem pendidikan, dan pengeluaran per kapita per tahun mengalami penurunan.

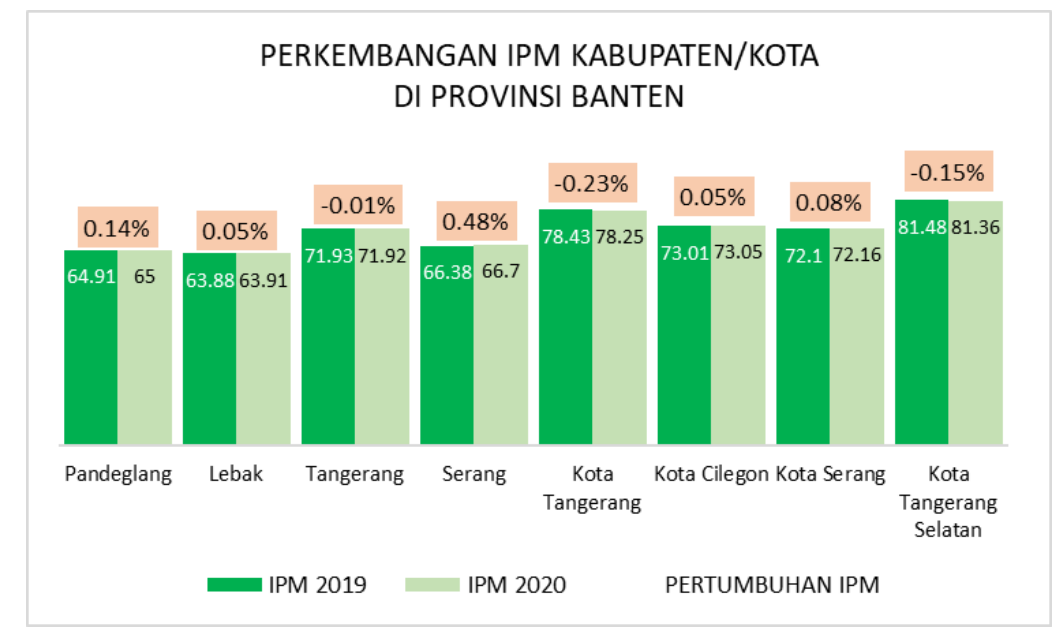

Gambar 3. Perkembangan IPM Kabupaten/Kota di Provinsi Banten Tahun 2019-2020 
Jurnal Lebesgue: Jurnal Ilmiah Pendidikan Matematika, Matematika dan Statistika

Rindang Ndaru Puspita, S.Si.

Volume 2, No. 3, Desember 2021 hal.267-281

DOI Artikel: 10.46306/lb.v2i3.85

Jika dilihat lebih detail pada Gambar 3, meningkatnya IPM di wilayah Provinsi Banten tahun 2020 hanya di 5 Kabupaten/Kota. Kabupaten Tangerang, Kota Tangerang dan Kota Tangerang selatan mengalami penurunan IPM pada tahun 2020.

Perlu dilakukan analisis lebih dalam untuk mengetahui karakteristik indikator-indikator penyusun IPM di Kabupaten/Kota sebagai penyumbang nilai IPM Provinsi Banten, agar dapat dilakukan upaya untuk peningkatan pembangunan manusia sebagai bukti peningkatan kesejahteraan masyarakat di wilayah Provinsi Banten. Pengelompokan Kabupaten/Kota berdasarkan kemiripan karakteristik indikator penyusun IPM dilakukan sebagai pertimbangan dalam perencanaan dan evaluasi pembangunan di daerah sebagai upaya meningkatkan indeks pembangunan manusia dan mengurangi kesenjangan antar daerah di Provinsi Banten. Maka dari itu, digunakan analisis statistik yaitu metode $K$-Means yang merupakan bagian dari analisis Cluster untuk mengelompokkan Kabupaten/Kota berdasarkan indikator penyusun IPM. Dalam metode $K$-Means akan ditentukan 3 cluster agar Pemerintah Provinsi Banten dapat lebih fokus dalam mementukan kebijakan pada Kabupaten/Kota berdasarkan karakteristik masing-masing cluster.

Pada penelitian ini dibahas tentang manfaat algoritma clustering dalam metode $K$-Means Cluster untuk mengelompokkan Kabupaten/Kota di Provinsi Banten berdasarkan kemiripan karakteristik daerah yang ditinjau dari empat indikator penyusun IPM yaitu Umur Harapan Hidup saat Lahir (UHH), Rata-Rata Lama Sekolah (RLS), Harapan Lama Sekolah (HLS) dan Pengeluaran Riil per Kapita per Tahun yang Disesuaikan.

\section{METODE PENELITIAN}

\section{Kajian Teori}

\section{Analisis Cluster}

Dalam penelitian ini digunakan metode analisis Cluster. Analisis Cluster memiliki tujuan untuk mengelompokkan objek berdasarkan karakteriktik yang sama. Menurut (Santoso, 2002) analisis cluster memiliki homogenitas atau kemiripan yang tinggi antar anggota dalam satu cluster, serta heterogenitas atau perbedaan yang tinggi antar cluster satu dengan yang lain. Metode dalam analisis cluster antara lain:

1. Metode Hierarki adalah teknik clustering berdasarkan tingkatan tertentu, cara pengelompokkan dilakukan bertahap, kemudian hasilnya ditampilkan dalam bentuk dendogram. 
Jurnal Lebesgue: Jurnal Ilmiah Pendidikan Matematika, Matematika dan Statistika

Rindang Ndaru Puspita, S.Si.

Volume 2, No. 3, Desember 2021 hal.267-281

DOI Artikel: 10.46306/lb.v2i3.85

2. Metode Non Hierarki adalah teknik clustering dengan mengasumsikan jumlah cluster yang diharapkan pada akhir pengelompokan. Pusat cluster yang dipilih adalah pusat cluster sementara yang terus diperbaharui untuk setiap iterasi sampai dengan kriteria tercapai, sehingga terdapat kemungkinan jika objek berpindah antara satu cluster ke cluster lainnya. Metode non hierarki yang popular adalah K-Means Cluster.

\section{K-Means Cluster}

Metode $K$-Means Cluster dirancang untuk mengelompokkan item, bukan variabel ke dalam cluster yang telah ditentutan jumlahnya di awal (Johnson, 2002). Menurut (Witten, 2012), $K$ Means merupakan salah satu algoritma untuk mengelompokkan data berdasarkan jarak dengan membagi data ke beberapa cluster serta algoritma hanya dapat bekerja pada data numerik. (Wakhidah, 2010) menjelaskan tahapan dalam algoritma $K$-means clustering sebagai berikut:

1. Menentukan jumlah cluster

2. Melakukan standarisasi data yaitu transformasi ke bentuk Z-Score jika terdapat perbedaan ukuran satuan yang besar pada data antar variabel. Standarisasi menggunakan rumus Z-Score yaitu

$Z_{i}=$

$\frac{x_{i}-\bar{x}}{S}$

dimana:

$Z_{i}=$ Nilai Z-Score ke-i

$x_{i}=$ Nilai data ke-i

$x_{i}=$ Nilai rata-rata

$S=$ Nilai standart deviasi

$i=1,2,3 \ldots \mathrm{n}$

3. Menentukan nilai centroid untuk awal iterasi secara acak. Selanjutnya jika menentukan nilai centroid yang merupakan tahap dari iterasi, dapat digunakan rumus

$$
\bar{V}_{i j}=
$$

$\frac{1}{N_{i}} \sum_{k=0}^{N_{i}} x_{k j}$

dimana:

$\bar{V}_{i j}=$ centroid/ rata-rata cluster ke-i untuk variabel ke-j 
Jurnal Lebesgue: Jurnal Ilmiah Pendidikan Matematika, Matematika dan Statistika

Rindang Ndaru Puspita, S.Si.

Volume 2, No. 3, Desember 2021 hal.267-281

DOI Artikel: 10.46306/lb.v2i3.85

$i, k=$ indeks dari cluster $\mathrm{j}$ adalah indeks dari variabel

$N_{i} \quad$ = jumlah data yang menjadi anggota cluster ke-i

$x_{k j}=$ nilai data ke-k yang ada di dalam cluster tersebut untuk variable ke-j

4. Menghitung Euclidean Distance untuk mengetahui jarak antara titik centroid dengan titik tiap objek menggunakan, yaitu

$$
\begin{aligned}
& D_{e}= \\
& \sqrt{\left(x_{i}-s_{i}\right)^{2}+\left(y_{i}-t_{i}\right)^{2}} .
\end{aligned}
$$

dimana:

$D_{e} \quad=$ Euclidean Distance

$i \quad=$ banyaknya objek $(0,1,2 \ldots \mathrm{n})$

$(s, t)=$ koordinat centroid

$(x, y)=$ koordinat objek

5. Pengelompokan objek dalam menentukan anggota cluster dengan menghitung jarak minimum objek. Nilai yang diperoleh adalah 0 atau 1 , nilai 1 berarti data yang dialokasikan ke cluster dan nilai 0 data yang dialokasikan ke cluster yang lain.

6. Kembali ke tahap 2, melakukan repetisi sampai diperoleh nilai centroid tetap dan anggota cluster tidak berpindah ke cluster yang lain.

Berdasarkan tahapan algoritma $K$-means clustering diatas, selanjutnya diterapkan dalam analisa data IPM Provinsi Banten tahun 2020 untuk mengelompokkan Kabupaten/Kota di Provinsi Banten berdasarkan kemiripan karakteristik daerah yang ditinjau dari empat indikator penyusun IPM. 
Jurnal Lebesgue: Jurnal Ilmiah Pendidikan Matematika, Matematika dan Statistika

Rindang Ndaru Puspita, S.Si.

Volume 2, No. 3, Desember 2021 hal.267-281

DOI Artikel: 10.46306/lb.v2i3.85

\section{Ruang Lingkup dan Sumber Data}

Data indikator IPM tahun 2020 dalam penelitian merupakan data sekunder yang diambil dari data Badan Pusat Statistik, dimana variabel yang digunakan sebagai berikut:

$X_{1}=$ Umur Harapan Hidup saat Lahir (UHH)

$X_{2}=$ Harapan Lama Sekolah (HLS)

$X_{3}=$ Rata-Rata Lama Sekolah (RLS)

$X_{4}=$ Pengeluaran Riil per Kapita per Tahun yang Disesuaikan

Detail data dari masing-masing variabel penyusun indikator IPM dapat diliat pada tabel dibawah:

Tabel 2. Data Indikator IPM

\begin{tabular}{|c|c|c|c|c|}
\hline Kabupaten/ Kota & UHH & HLS & RLS & Pengeluaran Riil Per Kapita \\
\hline \multirow{2}{*}{ Pandeglang } & 64.6 & 13.4 & \multirow{2}{*}{7.1} & \multirow{2}{*}{8572} \\
\hline & 6 & 7 & & \\
\hline \multirow{2}{*}{ Lebak } & 67.2 & 11.9 & \multirow{2}{*}{6.4} & \multirow{2}{*}{8690} \\
\hline & 1 & 7 & & \\
\hline \multirow{2}{*}{ Tangerang } & 69.8 & 12.8 & \multirow{2}{*}{8.39} & \multirow{2}{*}{12203} \\
\hline & 9 & 2 & & \\
\hline \multirow{2}{*}{ Serang } & 64.6 & 12.5 & \multirow{2}{*}{7.5} & \multirow{2}{*}{10665} \\
\hline & 4 & 7 & & \\
\hline \multirow{2}{*}{ Kota Tangerang } & \multirow{2}{*}{71.6} & 13.8 & 10.6 & \multirow{2}{*}{14484} \\
\hline & & 5 & 9 & \\
\hline \multirow{2}{*}{ Kota Cilegon } & 66.6 & 13.1 & \multirow{2}{*}{9.87} & \multirow{2}{*}{13010} \\
\hline & 7 & 6 & & \\
\hline \multirow{2}{*}{ Kota Serang } & \multirow{2}{*}{68} & 12.7 & \multirow{2}{*}{8.76} & \multirow{2}{*}{13212} \\
\hline & & 8 & & \\
\hline Kota Tangerang & 72.4 & 14.4 & 11.8 & \multirow{2}{*}{15667} \\
\hline Selatan & 7 & 7 & 1 & \\
\hline
\end{tabular}

\section{HASIL DAN PEMBAHASAN}

Dilakukan analisis pada data indikator IPM Provinsi Banten 2020 dengan metode $K$-Means Cluster dengan langkah awal yaitu menentukan jumlah cluster yang akan dibentuk adalah 3 cluster. Standardisasi data dengan transformasi ke bentuk Z-Score dilakukan terlebih dahulu 
Jurnal Lebesgue: Jurnal Ilmiah Pendidikan Matematika, Matematika dan Statistika

Rindang Ndaru Puspita, S.Si.

Volume 2, No. 3, Desember 2021 hal.267-281

DOI Artikel: 10.46306/lb.v2i3.85

karena terdapat perbedaan ukuran satuan yang besar pada data antar variabel agar tidak menyebabkan bias pada analisis cluster. Selanjutnya baru dilakukan analisis pada data yang telah distandardisasi menggunakan $K$-Means Cluster.

Tabel 2. Output Descriptive Statistics

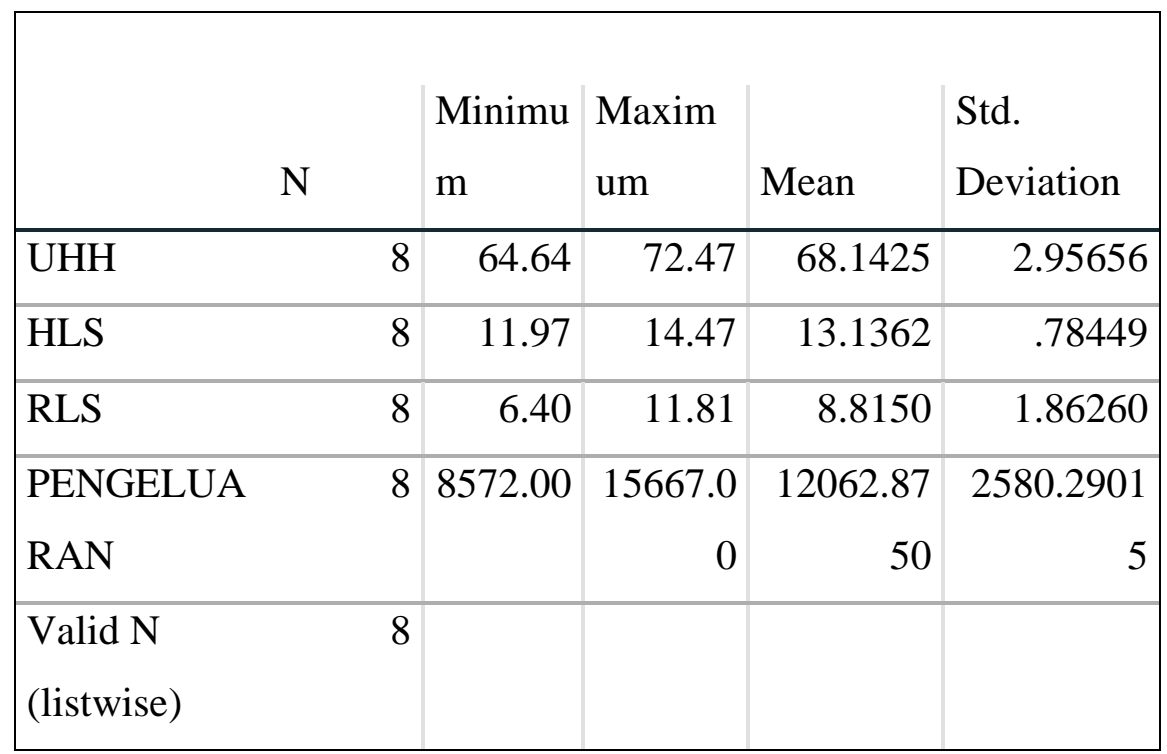

Pada tabel 2 dapat dilihat nilai descriptive statistics dari masing-masing indikator UHH, HLS, RLS, serta pengeluaran per kapita berdasarkan 8 data Kabupaten/Kota di Provinsi Banten yang memuat nilai maksimum, minimum, rata-rata dan standart deviasi.

Tabel 3. Output Initial Cluster Centers

\begin{tabular}{|lr|r|l|}
\hline & \multicolumn{3}{c|}{ Cluster } \\
& 1 & 2 & 3 \\
\hline Zscore(UHH) & -1.17789 & -.04820 & 1.46369 \\
\hline Zscore(HLS) & .42543 & -.45412 & 1.70015 \\
\hline Zscore(RLS) & -.92076 & -.02953 & 1.60797 \\
\hline Zscore(PENGELUAR & -1.35290 & .44535 & 1.39679 \\
AN) & & & \\
\hline
\end{tabular}

Pada tabel 3 dapat diketahui tampilan awal proses clustering yaitu hasil sementara proses pengelompokan data sebelum dilakukan proses iterasi yang menunjukan nilai pusat atau 
Jurnal Lebesgue: Jurnal Ilmiah Pendidikan Matematika, Matematika dan Statistika

Rindang Ndaru Puspita, S.Si.

Volume 2, No. 3, Desember 2021 hal.267-281

DOI Artikel: 10.46306/lb.v2i3.85

centroid cluster awal dari data yang sebelumnya telah dilakukan standarisasi.

Tabel 4. Output Iteration History

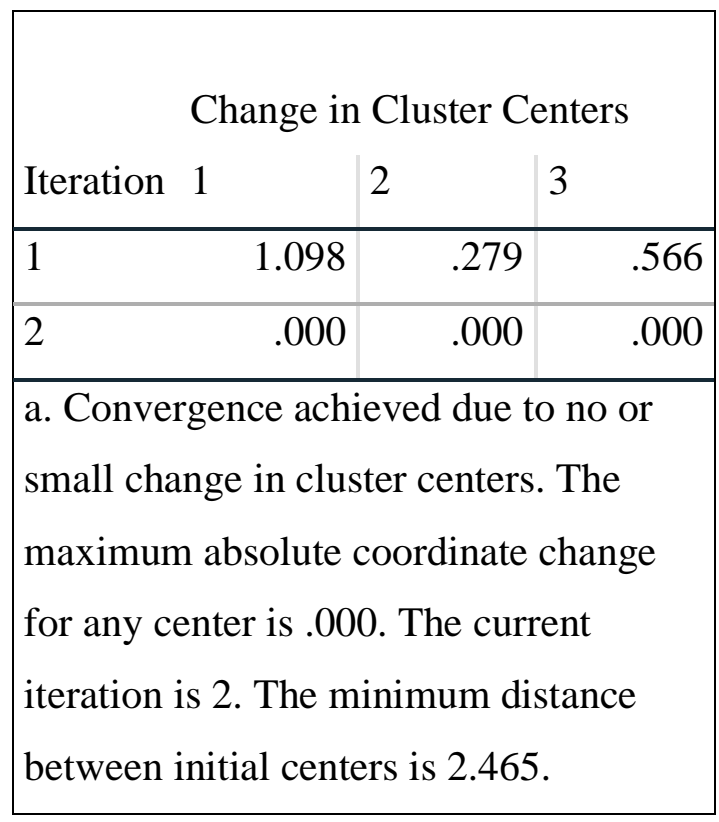

Berdasarkan tabel 4 diketahui proses iterasi dilakukan sebanyak dua kali untuk memperoleh cluster yang tepat serta jarak minimum antar pusat cluster berdasarkan hasil iterasi yaitu 2,465.

Tabel 5. Output Final Cluster Centers

\begin{tabular}{|lr|r|r|}
\hline & \multicolumn{3}{c|}{ Cluster } \\
& 1 & 2 & 3 \\
\hline Zscore(UHH) & -.89265 & .01494 & 1.31656 \\
\hline Zscore(HLS) & -.59433 & -.27566 & 1.30499 \\
\hline Zscore(RLS) & -.97444 & .10290 & 1.30731 \\
\hline Zscore(PENGELUAR & -1.06727 & .28890 & 1.16755 \\
AN) & & & \\
\hline
\end{tabular}

Pada tabel 5 diketahui nilai pusat cluster akhir dari proses clustering dimana data masih terdapat keterkaitan dengan standardisasi yang ditunjukkan dengan nilai z-score dengan makna

Nilai Zscore positif $(+)=$ data diatas rata-rata keseluruhan

Nilai Zscore negatif $(-)=$ data dibawah rata-rata keseluruhan 
Jurnal Lebesgue: Jurnal Ilmiah Pendidikan Matematika, Matematika dan Statistika

Rindang Ndaru Puspita, S.Si.

Volume 2, No. 3, Desember 2021 hal.267-281

DOI Artikel: 10.46306/lb.v2i3.85

Selanjutnya dapat diinterpretasikan hasil akhir analisis cluster dengan K-Means Cluster sebagai berikut:

1.Cluster 1 berisi nilai rata-rata indikator penyusun IPM yaitu UHH (-0.89265), HLS (0.59433), RLS (-0.97444), dan pengeluaran riil per kapita(-1.06727). Semua nilai ratarata indikator bernilai negatif yang berarti data UHH, HLS, RLS, dan pengeluaran riil per kapita dibawah rata-rata keseluruhan, sehingga dapat disimpulkan Cluster 1 berisi rata-rata nilai indikator penyusun IPM rendah.

2.Cluster 2 nilai rata-rata indikator penyusun IPM yaitu UHH (0.01494), HLS (-0.27566), RLS (0.10290), dan pengeluaran riil per kapita(0.28890). Jika dilihat dari nilai rata-rata HLS dibawah rata-rata keseluruhan dan UHH, RLS, pengeluaran riil per kapita diatas rata-rata keseluruhan. Sehingga dapat disimpulkan Cluster 2 berisi rata-rata nilai indikator penyusun IPM sedang.

3.Cluster 3 berisi nilai rata-rata indikator penyusun IPM yaitu UHH (1.31656), HLS (1.30499), RLS (1.30731), dan pengeluaran riil per kapita (1.16755). Semua nilai ratarata indikator bernilai positif yang berarti data UHH, HLS, RLS, dan pengeluaran riil per kapita pada cluster 3 diatas rata-rata keseluruhan. Sehingga dapat disimpulkan Cluster 3 berisi rata-rata nilainindikator penyusun IPM tinggi.

Tabel 6. Output ANOVA

\begin{tabular}{|c|c|c|c|c|c|c|}
\hline & $\begin{array}{l}\text { Cluster } \\
\text { Mean Square }\end{array}$ & df & $\begin{array}{l}\text { Error } \\
\text { Mean } \\
\text { Square }\end{array}$ & df & $\mathrm{F}$ & Sig. \\
\hline Zscore(UHH) & 2.929 & 2 & .228 & 5 & 12.821 & .011 \\
\hline Zscore(HLS) & 2.347 & 2 & .461 & 5 & 5.088 & .062 \\
\hline Zscore(RLS) & 3.149 & 2 & .140 & 5 & 22.447 & .003 \\
\hline $\begin{array}{l}\text { Zscore(PENGELUAR } \\
\text { AN) }\end{array}$ & 3.197 & 2 & .121 & 5 & 26.377 & .002 \\
\hline
\end{tabular}

Berdasarkan tabel 6 diketahui nilai $\mathrm{F}$ dan nilai probabilitas (.Sig) untuk mengetahui perbedaan variabel dari cluster yang dibentuk. Semakin besar nilai F serta nilai. Sig kurang dari 
Jurnal Lebesgue: Jurnal Ilmiah Pendidikan Matematika, Matematika dan Statistika

Rindang Ndaru Puspita, S.Si.

Volume 2, No. 3, Desember 2021 hal.267-281

DOI Artikel: 10.46306/lb.v2i3.85

0.05 maka berarti semakin heterogen karakteristik variabel antar cluster atau semakin besar perbedaan variabel antar cluster yang terbentuk.

Maka berdasarkan hasil pada tabel 6 disimpulkan bahwa tidak terdapat perbedaan signifikan pada variabel HLS di Cluster 1,2 dan 3. Selanjutnya pada variabel UHH, RLS, dan Pengeluaran Riil per Kapita per Tahun ada perbedaan signifikan di Cluster 1,2,3 dengan nilai perbedaan paling besar antar cluster yang terbentuk yaitu variabel Pengeluaran Riil per Kapita per Tahun karena memiliki nilai F paling besar yaitu 26.377. Sehingga antar cluster 1,2,3 heterogenitas atau perbedaan karakteristik antar cluster dikarenakan perbedaan karakteristik variabel UHH, RLS, dan Pengeluaran Riil per Kapita per Tahun.

Tabel 7. Output Number of Cases in each Cluster

\begin{tabular}{|llr|}
\hline Cluster & 1 & 3.000 \\
\cline { 2 - 3 } & 2 & 3.000 \\
\cline { 2 - 3 } & 3 & 2.000 \\
\hline Valid & & 8.000 \\
\hline Missing & & .000 \\
\hline
\end{tabular}

Diperoleh informasi pada tabel 7 yaitu jumlah anggota setiap cluster. cluster 1 memiliki jumlah anggota 3 Kabupaten/Kota, cluster 2 memiliki jumlah anggota 3 Kabupaten/Kota, cluster 3 t memiliki jumlah anggota 2 Kabupaten/Kota. Kemudian untuk mengetahui detail Kabupaten/Kota masing-masing cluster dapat dilihat di tabel 8.

Tabel 8. Komposisi Cluster

\begin{tabular}{|l|l|l|}
\hline \multicolumn{1}{|c|}{ Kabupaten/Kota } & Cluster & Jarak ke Pusat Cluster \\
\hline Pandeglang & 1 & 1.09807 \\
\hline Lebak & 1 & 1.1361 \\
\hline Tangerang & 2 & 0.71611 \\
\hline Serang & 1 & 0.67063 \\
\hline Kota Tangerang & 3 & 0.56634 \\
\hline Kota Cilegon & 2 & 0.76006 \\
\hline Kota Serang & 2 & 0.27901 \\
\hline Kota Tangerang Selatan & 3 & 0.56634 \\
\hline
\end{tabular}


Jurnal Lebesgue: Jurnal Ilmiah Pendidikan Matematika, Matematika dan Statistika

Rindang Ndaru Puspita, S.Si.

Volume 2, No. 3, Desember 2021 hal.267-281

DOI Artikel: 10.46306/lb.v2i3.85

Dapat dilihat pada tabel 8 bahwa pada kolom cluster menunjukkan nomor cluster dari Kabupaten/Kota, dan kolom Jarak ke Pusat Cluster menunjukkan jarak terdekat antara data dengan pusat cluster, dimana semakin kecil berarti semakin mirip dengan cluster terkait. Dengan demikian dapat diinterpretasikan sebagai berikut:

Cluster 1: Kabupaten Pandeglang, Kabupaten Lebak, dan Kabupaten Serang. Jarak ke pusat cluster 1 adalah 1,09807; 1,1361; dan 0,67063. Jarak ke pusat cluster 1 Kabupaten Pandeglang dan Kabupaten Lebak tidak berbeda jauh sehingga dapat disimpulkan karakteristik di cluster 1 yg mirip adalah Kabupaten Pandeglang dan Lebak.

Cluster 2: Kabupaten Tangerang, Kota Cilegon, dan Kota Serang. Jarak ke pusat cluster 2 adalah 0,71611;0,76006; dan 0,27901. Jarak terkecil ke pusat cluster 2 Kabupaten Tangerang dan Kota Cilegon tidak berbeda jauh sehingga dapat disimpulkan karakteristik di cluster 2 yg mirip adalah Kabupaten Tangerang dan Kota Cilegon.

Cluster 3: Kota Tangerang dan Kota Tangerang Selatan. Jarak ke pusat cluster 3 adalah 0,56634 dan 0,56634. Jarak ke pusat cluster 3 dari kedua kota hampir mirip sehingga dapat disimpulkan kedua kota yaitu Kota Tangerang dan Kota Tangerang Selatan sangat mirip karakteristiknya.

\section{KESIMPULAN}

Berdasarkan hasil penelitian yang dilakukan dengan K-Means Cluster pada data indikator penyusun IPM Kabupaten/Kota di Provinsi Banten Tahun 2020, diperoleh kesimpulan pengelompokan Kabupaten/Kota berdasarkan indikator Umur Harapan Hidup saat Lahir (UHH), Rata-Rata Lama Sekolah (RLS), Harapan Lama Sekolah (HLS) dan Pengeluaran Riil per Kapita per Tahun yang Disesuaikan diperoleh 3 Cluster sebagai berikut:

1. Cluster 1 yaitu Kabupaten/Kota dengan indikator IPM rendah, yaitu Kabupaten Pandeglang, Kabupaten Lebak, dan Kabupaten Serang, hal ini dikarenakan karakteristik Kabupaten/ Kota di cluster 1 memiliki kesamaan karakteristik yaitu nilai semua indikator IPM paling rendah jika dibandingkan dengan nilai indikator pada cluster lain.

2. Cluster 2 yaitu Kabupaten/Kota dengan indikator IPM sedang, yaitu Kabupaten Tangerang, Kota Cilegon, dan Kota Serang, hal ini dikarenakan karakteristik Kabupaten/ Kota di cluster 2 memiliki kesamaan karakteristik yaitu nilai semua indikator IPM di 
Jurnal Lebesgue: Jurnal Ilmiah Pendidikan Matematika, Matematika dan Statistika

Rindang Ndaru Puspita, S.Si.

Volume 2, No. 3, Desember 2021 hal.267-281

DOI Artikel: 10.46306/lb.v2i3.85

tengah-tengah jika dibandingkan nilai indikator pada cluster lain.

3. Cluster 3 yaitu Kabupaten/Kota dengan indikator IPM tinggi yaitu Kota Tangerang dan Kota Tangerang Selatan, hal ini dikarenakan karakteristik Kabupaten/ Kota di cluster 2 memiliki kesamaan karakteristik yaitu nilai semua indikator IPM paling tinggi jika dibandingkan nilai indikator pada cluster lain.

Setelah diketahui hasil pengelompokkan berdasarkan kesamaan karakteristik indikator IPM Kabupaten/Kota untuk masing-masing cluster, maka pemerintah Provinsi Banten dapat memberikan arahan dan kebijakan yang sesuai dengan karakteristik masing-masing cluster kepada masing-masing Kabupaten/Kota di Cluster 1 dan 2 untuk dapat meningkatkan Indeks Pembangunan Manusia di wilayahnya dengan lebih memperhatikan penyusunan program kegiatan yang berkaitan dengan indikator penyusun IPM.

\section{DAFTAR PUSTAKA}

Alwi, W \& Hasrul, M (2018). Analisis Klaster untuk Pengelompokan Kabupaten/Kota di Propinsi Sulawesi Selatan Berdasarkan Indikator Kesejahteraan Rakyat. Jurnal MSA, Vol 6 No 1: 35-42.

Badan Pusat Statistik. (2020). Indeks Pembangunan Manusia 2020. Jakarta: Badan Pusat Statistik.

Dhuhita, W. M. P. (2015). Clustering Menggunakan Metode K-Means untuk Menentukan Status Gizi Balita. Jurnal Informatika, 15(2): 160-174.

Johnson, R. A. \& Wichern, D. W. (2002). Applied Multivariate Statistical Analysis, Fifth Edition. New Jersey: Pearson Prentice Inc.

Mayasari, T. R. (2019). Clustering Akses Air Bersih dan Sanitasi Layak Kabupaten/Kota di Provinsi Lampung. Jurnal Aplikasi Statistika dan Komputasi Statistik, Vol 2019 No 1: 563572.

Novidianto, R. \& Dani, A. T. R (2020). Analisis Cluster Kasus Aktif Covid-19 Menurut Provinsi di Indonesia Berdasarkan Data Deret Waktu. Jurnal Aplikasi Statistika dan Komputasi Statistik, V.12.2.2020: 15-24.

Safe'i, A.I. (2018). Aplikasi K-Means untuk Pengelompokan Kabupaten dan Kota Berdasarkan Produktivitas Tanaman Pangan di Provinsi Jawa Tengah Tahun 2015. Skripsi Universitas Islam Indonesia. Yogyakarta. $80 \mathrm{hlm}$.

Safitri, D, Widiharih, T, Wilandari, Y. \& Saputra, A. H. (2012). Analisis Cluster Kabupaten/Kota di Jawa Tengah Berdasarkan Produksi Palawija. Jurnal Media Statistika, Vol 5 No 1: 11-16.

Saki, D. A. L, Jayanti, N. A. \& Nurmayanti, W. P. (2020). Clustering Petani Berdasarkan Dampak Covid-19 yang Terjadi pada Sektor Pertanian. Jurnal Aplikasi Statistika dan Komputasi Statistik, V.12.2.2020:160-164.

Santoso, Singgih. (2002). Buku Latihan SPSS Statistika Multivariat. Jakarta: PT Elex Media Komputindo.

Wakhidah, Nur. (2010). Clustering Menggunakan K-Means Algorithm. Jurnal Transformatika, 8(1): 45-52. 
Jurnal Lebesgue: Jurnal Ilmiah Pendidikan Matematika, Matematika dan Statistika

Rindang Ndaru Puspita, S.Si.

Volume 2, No. 3, Desember 2021 hal.267-281

DOI Artikel: 10.46306/lb.v2i3.85

Witten, H.I. \& Frank, E. (2012). Data Mining Practical Machine Learning Tools and Technique, 2nd Edition. San Faransisco: Morgan Kaufmann. 